DOI: $10.1515 /$ rpp-2015-0039

Doctor of Pedagogical Sciences, Full Professor, IRYNA KOZUBOVSKA

Uzhgorod National University, Ukraine

Address: 3 Narodna Sq, Uzhgorod, 88000, Ukraine

E-mail:kozub@hotmail.com

Postgraduate student, IRYNA POPOVYCH

Uzhgorod National University, Ukraine

Address: 3 Narodna Sq, Uzhgorod, 88000, Ukraine

E-mail: Irene-P@mail.ru

\title{
TRAINING OF TEACHER-RESEARCHER AS PRIOR CONSIDERATION OF PROFESSIONAL TRAINING OF PEDAGOGUES IN GREAT BRITAIN
}

\begin{abstract}
The article is devoted to the problem of professional training of pedagogues in foreign countries. Special attention has been paid to the experience of Great Britain. It has been underlined that the teacher has to acquire thorough knowledge in profession as well as to master the methods of teaching. Nevertheless, this is not enough to reach success in a professional field. The educational system today needs a teacher-researcher. It has been proved that the process which provides scientific and educational unity by means of involving students into scientific work is stirring up in European pedagogical institutions. The problem of orientating the teachers to be on research work is considered to be the most important condition of their personal professional self-determination and professional culture. A new teacher-researcher training pattern in British higher educational system has been made. This pattern includes some interdependent components and is successful under certain pedagogic conditions: the possession of research position by a teacher-to-be; ensuring creative interaction and cooperation among students and teachers; introduction of special educative modules with research orientation; the use of project technologies; the arrangement of creative educational atmosphere; establishing friendly relationships among university teachers (lecturers), students and school teachers. The accent is made on the urgent necessity of implementation of British experience in Ukraine.

Key words: Great Britain, professional training of pedagogues, teacher-researcher, scientific skills, scientific activity, professional self-determination and professional culture, teacher-researcher training pattern, pedagogic conditions.

\section{INTRODUCTION}

The changes, presented in our society for the last decade, stipulate the growth of demands for professional training of pedagogues. There is no doubt that the teacher has to acquire thorough knowledge in profession as well as to master the methods of teaching. Nevertheless, this is not enough to reach success in a professional field. The educational system today needs a teacher-researcher. This also concerns Ukraine, where there is a huge gap in the requirements for the pedagogues, who obtained the research skills, and a current situation in professional training of a teacher-researcher. The experience in training of such a teacher has been accumulated by many European countries and Great Britain in particular. That is the reason we consider it to be expediently to analyze certain aspects of the British system of teacher-researcher training and to present the results in the article in
\end{abstract}


order to creatively comprehend and implement positive aspects of such experience in Ukraine.

THE AIM OF THE STUDY

The aim of the research is the analysis of the experience of teacher-researcher training in Western European countries and Great Britain in particular, certain positive aspects of which may be implemented in Ukraine.

THEORETICAL FRAMEWORK AND RESEARCH METHODS

The survey of the sources shows the deep interest of Ukrainian scientists in the problems of professional training of teacher in our country as well as abroad (V. Kravets, V. Kremen, N. Nychkalo, L. Puhovska, I. Zyazyun and others). For the last decade the training of a teacher-researcher has become the most topical issue (S. Honcharenko, V. Kulyk, A. Stepanyuk and others). However, the problem of formation of the research skills needs further investigation. We consider studying progressive foreign experience in professional training of a teacher-researcher to be expedient (D. Bond, F. Kerlinger, D. Laurillard, M. Smith).

To fulfill the aim a wide range of investigation methods has been involved (the method of analysis of philosophical, pedagogical, psychological and educational literature to define the notion of the research' main points; the method of conceptual and comparative analysis, system-structural analysis and synthesis for determination of theoreticallymethodological nature of the professional teacher-researcher training). The methodological basis of the research is the general philosophical ideas of humanization and internationalization of education.

\section{RESULTS}

The survey of the scientific sources proves the fact that the process which provides scientific and educational unity by means of involving students into scientific work is stirring up in European pedagogical institutions. The problem of orientating the teachers to be on research work is considered to be the most important condition of their personal professional self-determination and professional culture (Smith, 1995; Block, Cameron, 2002; Laurillard, 1998).

At the end of XX - the beginning of XXI century the foreign pedagogical school revises aims and content of education. First of all, the question is about the formation of the student's creative potential, the necessity of self-perfection, and self-expression not only in college and university, but for a period of the whole life. There takes place the change of the aim of educational process from educative into developing, where the result is the model of expert corresponding to the following criteria: professional mobility, ability for adaptation to information space, high level of intelligence (IQ), knowledge and skills, creativity, critical thinking, self-dependence.

Nowadays one can observe the growth of activity of European students' participation in a wide range of forms of students' scientific work. There are large research database, problem laboratories and research teams in leading European universities. The fulfillment of a particular quantity of researches by students during the whole period of study was provided for curricula of the institutes of higher education in European countries. Investigations are not limited by writing a year paper or thesis, but the fulfillment of scientific research is also stipulated, which is included into the work plan of research team and research units at the institutes of higher education.

The students' research work during the period of study includes the following points:

- first-hand acquaintance with the methods of scientific work, methodological problems of study and scientific research;

- acquaintance with accepted concept and theories within disciplines; 
- understanding of conventions and structure of information within the subject;

- learning the ways to find and place the necessary material to carry out the research;

- critical reading of the material with further analysis and evaluation;

- structuring the material in order to formulate the fundamental tenets of the research;

- presenting (in oral or written form) one's own comprehension of a problem, analysis, interpretation of concept and theories under the research.

In European pedagogical institutions there is no absolute conformity of opinions concerning the problems in organization the students' research work and the use of the forms and methods of teaching. This can be easily explained by the fact that all the countries are developing in their own way according to their own traditions: cultural, political and social. However, general tendencies in organization of the students' research work have been designated. Determinative factor in training teachers-to-be is not the mere formation of particular knowledge, but the development of intelligence that is the result of the humanities knowledge and the ability for self-education. This leads to the use of new teaching technologies, which provide the discussion of the most difficult questions on the lectures and seminars, and the main bulk of information is formed as a result of independent research. Due to this factor, the number of lines is reduced and attention is focused on independent research and the humanities component (Kerlinger, 2002).

The analysis of the curricula of some European countries has indicated the fact that the quantity of the compulsory general theoretic and scientific disciplines comprises $50-60 \%$ of the total amount of curricula. Moreover, the optional courses and elective disciplines, which meet the students' individual interests and needs, are gradually increasing. This fact ensures the fulfillment of their (students') individual research work and specialization in different fields. In most of the contemporary projects, elaborated for the pedagogical education in Europe, one of the most important points in professional training is active teaching which includes a wide range of teaching styles, making a student an active participant of a teaching process. Active learning presupposes the students' understanding of practical use of knowledge obtained and the ability to put questions to the material which, to their mind, have not been elucidated enough in the lecture.

Inquiry-based learning, collaborative learning and constructivism are the most widespread forms of active learning, where the student goes through the investigative process for the discovery and rediscovery of knowledge.

As a result of studies at the institute of higher education a future teacher-researcher should obtain special knowledge and form the investigative skills.

Great Britain has a great experience in training teacher-researcher. It should be taken into the consideration that at the end of XX century in Great Britain the problem of correlation in teaching and research work in the work of contemporary teacher gained its actuality. In the early XXI century this problem already become of the utmost importance. Today in British educational system there is a demand for a teacher-researcher.

Practice-oriented approach in teaching, which is widespread in British educational system, aims to cultivate in students those competences on important value basis which they will need in future. Among them the most important are: active lifestyle, aspiration for scientific research, discoveries, ability to arrange work on one's own and original research within the studies (Boud, 1999).

The realization of teacher-researcher competence is the priority field of National Teacher Research Panel. National investment strategy in science and innovations among all the basic tasks takes into account a considerable growth of expenses to carry out researches; 
collaboration reinforcement among institutes of higher education and schools; the improvement of teachers' professional skills in high technology field.

Being a result of the transformation of the world's educational system as well as British one, nowadays a new research paradigm is becoming firmly established, the main task of which is to change accent in the position of a contemporary teacher: from mere functional fulfillment of the duties to the teacher-researcher, who has a huge creative potential, ability for reflexive thinking, constant self-education and self-perfection of the professional skills.

As a result of the analysis of scientific literature, it has been revealed that the research on the pedagogical investigative ground is traditionally regarded as learning the teacher's professional activity which provides the pedagogue's analysis and meditations on his work in order to improve it. This factor favours positive motivation of the participants of the educational process by means of reflection of the personal investigation results during the period of study at the institute of higher education as well as continuous education.

A new pedagogical phenomenon - "teaching-research nexus" is revealed in the works of British scientists (R. Barnet, L. Elton, D. Furlong, M. Hilly, E. Jenkins, L. Lukas and others) where the teacher's activity in sharing his experience with pupils at the lesson is closely connected with his investigations. Thus, the research process and pedagogical process are presented as the whole unit (Furlong, 2002).

Axiomatic basis in a notion "teaching -research nexus" is put into values that are divided into two groups: values of educational content and teacher's personal values (his points of view, position, principles). One cannot perceive traditional orientation of a contemporary educational system without trying to understand fundamental meaning of values in pedagogical research.

Recently British investigators have actively been using special scientific terminology: "value-based education" to indicate teacher's professional activity which is directed on forming and developing educational values at pupils' and "value-based teacher education" to indicate professional training of future teachers on the axiomatic basis which provides direction of attention toward professional and human values.

Modeling the teacher-training process in Great Britain is based on three patterns, suggested by the following British scientists S. Borg, D. Shon, E. Kemmbel:

- "effective teacher" whose activity is directed on creating positive atmosphere in a class, defining the pupil's abilities, favoring the development of the children's creative abilities;

- "reflexive teacher" who deeply comprehends his professional pedagogical activity and regularly appraises its results;

- "transformative teacher" who not only trains pupils for successful functioning in a society, but also takes an active position in his work and makes pupils to take an active part in public activities.

On the basis of these patterns a new teacher-researcher training pattern in British higher educational system has been made. This pattern includes the following interdependent parts:

- professional values i.e.: ethic component which is based on the integrity of knowledge about culture, values, social consciousness in professional practice;

- personal and professional qualities being a component of teacher's professional ability;

- a position of researcher which defines a teacher's ability for educational transformations;

- the key competences which are used by a teacher to reach the professional aim;

- research abilities (gnosiological, constructive, prognosticative, reflexive, communicative, perceptional, expressive, suggestive, etc.) which provide content, process and result of a research; 
- professional training technologies on the basis of research work;

- validity of the research results.

The suggested approximate pattern to a certain extent is used in most British institutes of higher education.

The pattern is effectively used under certain organization-pedagogical conditions: the possession of research position by a teacher-to-be; ensuring creative interaction and cooperation among students and teachers; introduction of special educative modules with research orientation; the use of project technologies; the arrangement of creative educational atmosphere; establishing friendly relationships among university teachers (lecturers), students and school teachers.

\section{CONCLUSIONS}

Nowadays in European educational system a new research paradigm is becoming firmly established. This paradigm presupposes the change of accents in position of a contemporary teacher. He is changed from a mere functional executor into a teacherresearcher, who possesses a considerable creative potential, ability for reflexive thinking, constant self-education and self-perfection of a professional teaching activity.

The problem of formation research skills of a teacher-to-be has been of the utmost importance in Great Britain. Thus, the pattern of professional teacher-researcher training has been worked out by British scientists, which we consider to be of great interest for educational system in Ukraine. The problem of implementation of the British experience of professional teacher-researcher training in Ukraine needs further investigation.

\section{REFERENCES}

1.Boud, D. J. (1999). Developing Student Autonomy in Learning. London : Kogan Page, p. 274.

2. Block, D., Cameron, D. (2002). Globalization and Language Teaching. London : Routledge, p. 196.

3.Furlong, J. (2002). Ideology and Reform in Teacher Education in England. Education Researches, Volume 31 (6), p. 23-25.

4. Kerlinger, F. N. (2002). Foundations of Behavioral Research. Educational and Psychological Enquiry. Halt, Rinehart and Winston, p. 140.

5.Laurillard, D. (1998). Rethinking University Teaching. A Framework for the Effective Use of Technology. London : Routledge, p. 240.

6. Smith, M. (1995). Professional Education in Britain. London : Allen and Unwin, p. 114. 